\title{
ZnO-Porous Clay Heterostructure from Saponite as Green Catalyst for Citronellal Cyclization
}

\author{
Dwiarso Rubiyanto ${ }^{1,2}$, Nurcahyo Iman Prakoso1,2, Imam Sahroni1, Rico Nurillahi', \\ Is Fatimah 1,2,*
}

${ }^{1}$ Chemistry Department, Universitas Islam Indonesia, Kampus Terpadu UII, Jl. Kaliurang Km 14, Sleman, Yogyakarta, Indonesia.

${ }^{2}$ Center of Essential Oil Studies, Universitas Islam Indonesia, Kampus Terpadu UII, Jl. Kaliurang Km 14, Sleman, Yogyakarta, Indonesia.

Received: 15th September 2019; Revised: $9^{\text {th }}$ November 2019; Accepted: $13^{\text {th }}$ November 2019; Available online: 28th February 2020; Published regularly: April 2020

\begin{abstract}
Green conversion in organic synthesis is one of the interesting and important topics in green chemistry. The use of heterogeneous catalysis instead of homogeneous catalysis offers some advantages, such as easy separation and reusability. In this research, a heterogeneous acid catalyst was prepared from saponite by immobilizing $\mathrm{ZnO}$ in the form of a pillared clay (Zn/PILS) and Zn supported on porous clay heterostructure $(\mathrm{Zn} / \mathrm{PCH})$. Physicochemical studies involving X-ray diffraction measurement, surface analysis using a gas sorption analyzer, and surface acidity measurement were performed. Results indicated that the increasing surface acidity and the high specific surface area of the material were the relevant physicochemical properties that facilitate environment-friendly citronellal cyclization. The higher values for both parameters in $\mathrm{Zn} / \mathrm{PCH}$ than in $\mathrm{Zn} / \mathrm{PILS}$ linearly affected citronellal conversion and the selectivity for isopulegol production. $\mathrm{Zn} / \mathrm{PCH}$ demonstrated a conversion rate of $98.9 \%$ for a 3 -hour reaction and a selectivity of $100 \%$ for isopulegol production, and it exhibited reusability properties. Copyright $@ 2020$ BCREC Group. All rights reserved
\end{abstract}

Abstract

Keywords: Citronellal; Cyclization; Pillared Clay; Porous Clay Heterostructure; $\mathrm{ZnO}$

How to Cite: Rubiyanto, D., Prakoso, N.I., Sahroni, I., Nurillahi, R., Fatimah, I. (2020). ZnO-Porous Clay Heterostructure from Saponite as Green Catalyst for Citronellal Cyclization. Bulletin of Chemical Reaction Engineering \& Catalysis, 15(1), 137-145 (doi:10.9767/bcrec.15.1.5800.137-145)

Permalink/DOI: https://doi.org/10.9767/bcrec.15.1.5800.137-145

\section{Introduction}

Citronellal is a component of lemon grass oil and is an important compound for several platforms used to produce some pharmaceuticals and toiletries. Citronellal can be converted into isopulegol through several mechanisms, one of which is isomerization over an acid catalyst [1]. This step is important given that other compounds, such as menthol, can be derived from isopulegol. The catalytic approach in the conversion of citronellal into isopulegol has been wide-

* Corresponding Author.

Email: isfatimah@uii.ac.id (I. Fatimah) ly studied. From the green chemistry perspective, the use of a heterogeneous catalyst instead of a homogeneous catalyst for such conversion has been considered, and the use of some alternative catalysts has been reported. Besides the economic value of catalysts, their high surface area, acidity, and stability are important properties to consider [2]. The formation of metal oxide pillared clays in some catalytic applications, including citronellal cyclization, was widely reported [3-5]. The preservation of surface Brønsted and Lewis acidities plays an important role in an effective and recyclable catalytic mechanism. In silica-alumina materials, clay-based catalysts exhibit a high surface area, 
and they are modifiable and reusable. Some modification schemes can be applied to identify more active catalysts for the homogeneous distribution of a metal or a metal oxide catalyst in a clay structure. Studies showed that the formation of metal oxide in the interlayer space of smectite clay structures provides stability and more importantly preserves the surface acidity in certain acid-catalyzed mechanisms [6-8]. Modification of a clay into a porous clay heterostructure $(\mathrm{PCH})$ was also reported. $\mathrm{PCH}$ attracts considerable interest for catalysis applications and has been reported in various reactions, including DeNOx process, dehydration, and photodegradation $[6,7,9,10]$.

High surface acidity and high surface area are the main factors influencing the increase in catalytic activity; moreover, the advantages of using $\mathrm{PCH}$ especially in preserving surface acidity in many catalytic mechanisms are mainly attributed to the tunable properties of $\mathrm{PCH}$. The combination of acid metal oxide and PCH was also notified to give mutual properties for some desirable properties in reactions, including the catalyst activity and selectivity refer to the presence of metal as active site specificity [11-13].

In industrial applications, citronellal conversion requires the use of a reusable, efficient, and effective acid catalyst instead of a nonreusable, corrosive homogeneous catalyst. Refer to the more general scheme, the combination of these characters in a heterogeneous catalyst in an organic reactions fulfill the principles of green chemistry, so called as green catalyst $[4,14,15]$.

Previous works reported on the use of saponite and pillared saponite; however, their reusability has not yet been investigated [16,17]. With the use of different synthesis routes and schemes, the surface area of a pillared form is not as high as that of $\mathrm{PCH}$. In other schemes, zinc catalyst is characteristically used in acid catalysis [18]. In order to explore the effectiveness of clay-based catalyst for citronellal conversion, this research aimed to prepare $\mathrm{Zn}$ supported on clay through pillarization (referred to as $\mathrm{ZnO}$ pillared saponite (Zn/PILS)) and $\mathrm{Zn}$ supported on $\mathrm{PCH}(\mathrm{Zn} / \mathrm{PCH})$. Moreover, this research compared the catalytic activity of $\mathrm{Zn} /$ PILS and $\mathrm{Zn} / \mathrm{PCH}$ in terms of physicochemical properties, particularly surface acidity and catalytic activity.

\section{Materials and Methods}

\subsection{Materials}

The clay mineral used to synthesize $\mathrm{PCH}$ was saponite (Sumecton SA), which was obtained from Kuninime Industrial Company (Tokyo, Japan). Hexadecyltrimethylammonium bromide (CTMBr) (99\%), isopropanol (99.9\%), pyridine, trimethanolamine (TMA) (90\%), tetraethylorthosilicate (TEOS) (98\%), and zinc acetate dihydrate were purchased from MerckMillipore (Germany), whereas citronellal (98\%) and isopulegol (98\%) were obtained from TCI (Tokyo, Japan).

\subsection{Materials Preparation}

$\mathrm{Zn} / \mathrm{PCH}$ was prepared as follows: $2.5 \mathrm{~g}$ saponite was mixed with $9 \mathrm{~g}$ CTMBr (Aldrich) in $300 \mathrm{~mL}$ distilled water and then stirred overnight. TMA (0.88 g) was added into the suspension and then stirred for $24 \mathrm{~h}$. The pillars were prepared by mixing $8.86 \mathrm{~g}$ zinc acetate dehydrate solution with $5 \mathrm{~mL}$ TEOS in isopropanol. The $\mathrm{Zn}$ content of PCH was set at $10 \%$ wt. The suspensions were kept under hydrothermal condition in an autoclave at $100{ }^{\circ} \mathrm{C}$ for $24 \mathrm{~h}$. Solids were obtained by filtering the suspension that was kept in the autoclave; the solids were washed with distilled water and ethanol and then air-dried at $60{ }^{\circ} \mathrm{C}$ for $12 \mathrm{~h}$ before being calcined at $500^{\circ} \mathrm{C}$ for $2 \mathrm{~h}$. The saponite was pillarized using similar procedure but without the addition of TMA and TEOS.

\subsection{Material Characterization}

Powder X-ray diffraction patterns of the samples were collected on a Rigaku Miniflex diffractometer equipped with $\mathrm{Cu}-\mathrm{K} \alpha$ radiation, and the diffractograms were recorded within the $2 \theta$ range of $3^{\circ}-80^{\circ}$ with a step size of $0.02^{\circ}$. Surface parameters (Brunauer-Emmett-Teller (BET)) surface area, pore volume, pore distribution, and pore radius) were evaluated from the nitrogen adsorption-desorption isotherms at $-77 \mathrm{~K}$ by an automatic ASAP 2020 system procured from Micromeritics (Norcross, GA, USA). Prior to the measurements, the samples were outgassed at $200{ }^{\circ} \mathrm{C}$ and at $10^{-4} \mathrm{mbar}$ overnight. Surface areas were determined using the BET equation, whereas the pore distribution of materials were calculated using the Barrett-Joyner-Halenda equation. Elemental analysis was performed using a Phenom $\mathrm{X}$ instrument (Singapore). Surface acidity of the materials was analyzed through $n$-butylamine back titration, with acetic acid as standard.

\subsection{Catalytic Activity Tests}

Catalytic activity in citronellal isomerization was tested by using a Reflux system. A 
catalyst ( $0.25 \mathrm{~g} ; 100$ mesh) was added into the citronellal solution in isopropanol $(10 \mathrm{~mL})$, and the mixture was refluxed for $3 \mathrm{~h}$. The reactants and products were analyzed by a gas chromatograph-mass spectrometer (Shimadzu). Catalytic conversion and selectivity during isopulegol ( $\left.\mathrm{S}_{\text {isopulegol }}\right)$ production were calculated based on the peak change in citronellal, isopulegol, and other products (Equations (1) and (2)):

$$
\begin{aligned}
& \text { Conversion }=\frac{A_{c i}-A_{c t}}{A_{c i}} \times 100 \% \\
& S_{\text {iso }}=\frac{A_{\text {iso }}}{A_{\text {total }}-A_{c t}} \times 100 \%
\end{aligned}
$$

With $A_{\text {ci }}$ is peak area of citronellal in initial reactant, $A_{\mathrm{ct}}$ is peak area of citronellal in chromatogram of product, $A_{\text {iso }}$ is peak area of isopulegol, and $A_{\text {total }}$ is total peak area chromatogram of product. Catalyst reusability test was performed by filtering the catalyst after use followed by washing with ethanol and drying at $80^{\circ} \mathrm{C}$ for $2 \mathrm{~h}$.

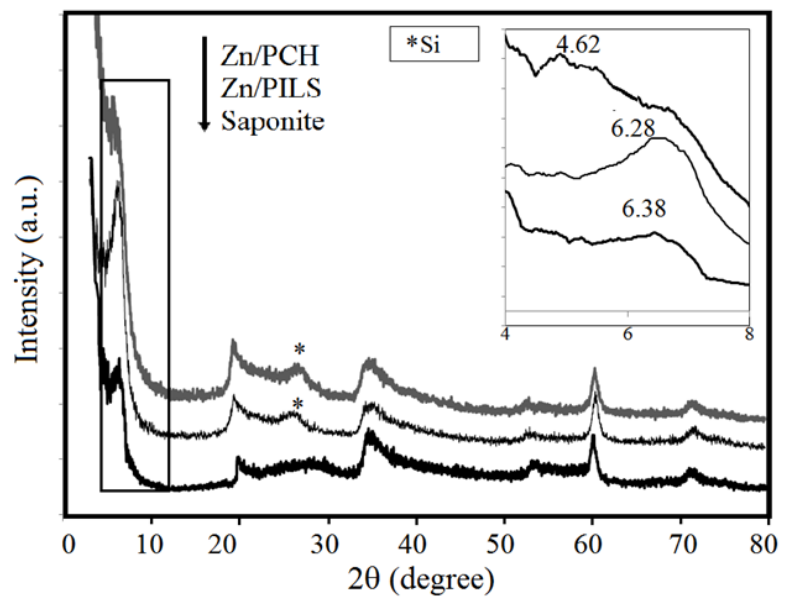

Figure 1. XRD pattern of materials.

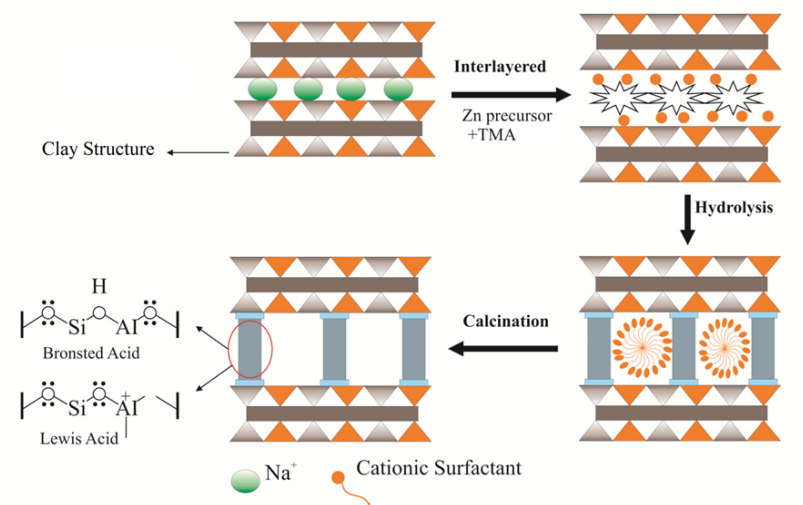

Figure 2. Schematic representation of $\mathrm{PCH}$ formation.

\section{Results and Discussion}

\subsection{Physicochemical Characterization}

Figure 1 and Table 1 show that the pillarization and $\mathrm{PCH}$ formation led to the increase in basal spacing do01 from $13.82 \AA$ in saponite to a maximum of $14.73 \AA$ in Zn/PILS and 19.08 $\AA$ in $\mathrm{Zn} / \mathrm{PCH}$. The increasing do01 pattern implies the formation of a space in the interlayer region, and this phenomenon was in turn influenced by another mechanism. The PCH formation is conducted due to the scheme in Figure 2 .

The formation of silica pillar after the intercalation resulting from the use of surfactant prior to the entry $\mathrm{ZnO}$ into the intra-gallery creates a larger intra-gallery space. For both the $\mathrm{Zn} / \mathrm{PILS}$ and $\mathrm{Zn} / \mathrm{PCH}$ samples, a broad reflection was observed at around $25^{\circ}{ }^{*}$ ), indicating the presence of silica in its elemental form in small amount and in its crystalline form, and this phenomenon is usually considered an effect of the formation of intra-gallery space during intercalation of the surfactant into a clay structure [20,21]. In this case, CTMA intercalation was utilized for both Zn/PILS and $\mathrm{Zn} / \mathrm{PCH}$ formation. Data suggested the homogeneous distribution of $\mathrm{ZnO}$ in the composite structure. The measured basal spacing is consistent with the TEM analysis results (Figure 3 ), suggesting that there are increasing gridlines representing the sheet structure with the width of about 17-19 $\AA$. This assumption is also consistent with the TEM image presented in Figure 3.

From the image, the formation of intergallery space is found as the lines formation in $\mathrm{Zn} / \mathrm{PCH}$ which is absence in saponite samples, with the space identified at around 1.70-1.9 $\mathrm{nm}$. The layered structures are appeared for saponite samples and by converting into $\mathrm{Zn} /$ $\mathrm{PCH}$, some spots exhibit the presence of $\mathrm{ZnO}$

Table 1. Elemental analysis of materials.

\begin{tabular}{cccc}
\hline \multirow{2}{*}{ Component } & \multicolumn{3}{c}{ Composition (\% at.) } \\
\cline { 2 - 4 } & Saponite & Zn/PILS & Zn/PCH \\
\hline $\mathrm{O}$ & 49.68 & 54.03 & 55.22 \\
$\mathrm{Na}$ & 3.23 & 1.09 & 0.03 \\
$\mathrm{Mg}$ & 8.3 & 9.18 & 7.18 \\
$\mathrm{Al}$ & 11.23 & 10.73 & 6.56 \\
$\mathrm{Si}$ & 27.51 & 19.69 & 17.65 \\
$\mathrm{Zn}$ & 0 & 5.28 & 6.52 \\
$\mathrm{C}$ & - & - & 6.05 \\
$\mathrm{~N}$ & - & - & 0.79 \\
\hline
\end{tabular}


particles. The presence of $\mathrm{Zn}$ in the modified saponite is confirmed by EDX analysis, and the spectra and data are presented in Figure 4 and Table 1 , respectively. The amounts of $\mathrm{Zn}$ in both $\mathrm{Zn} / \mathrm{PILS}$ and $\mathrm{Zn} / \mathrm{PCH}$ are similar due to the similar molar ratio used in the preparation, and the values are lower than the approached amount (10\%wt).
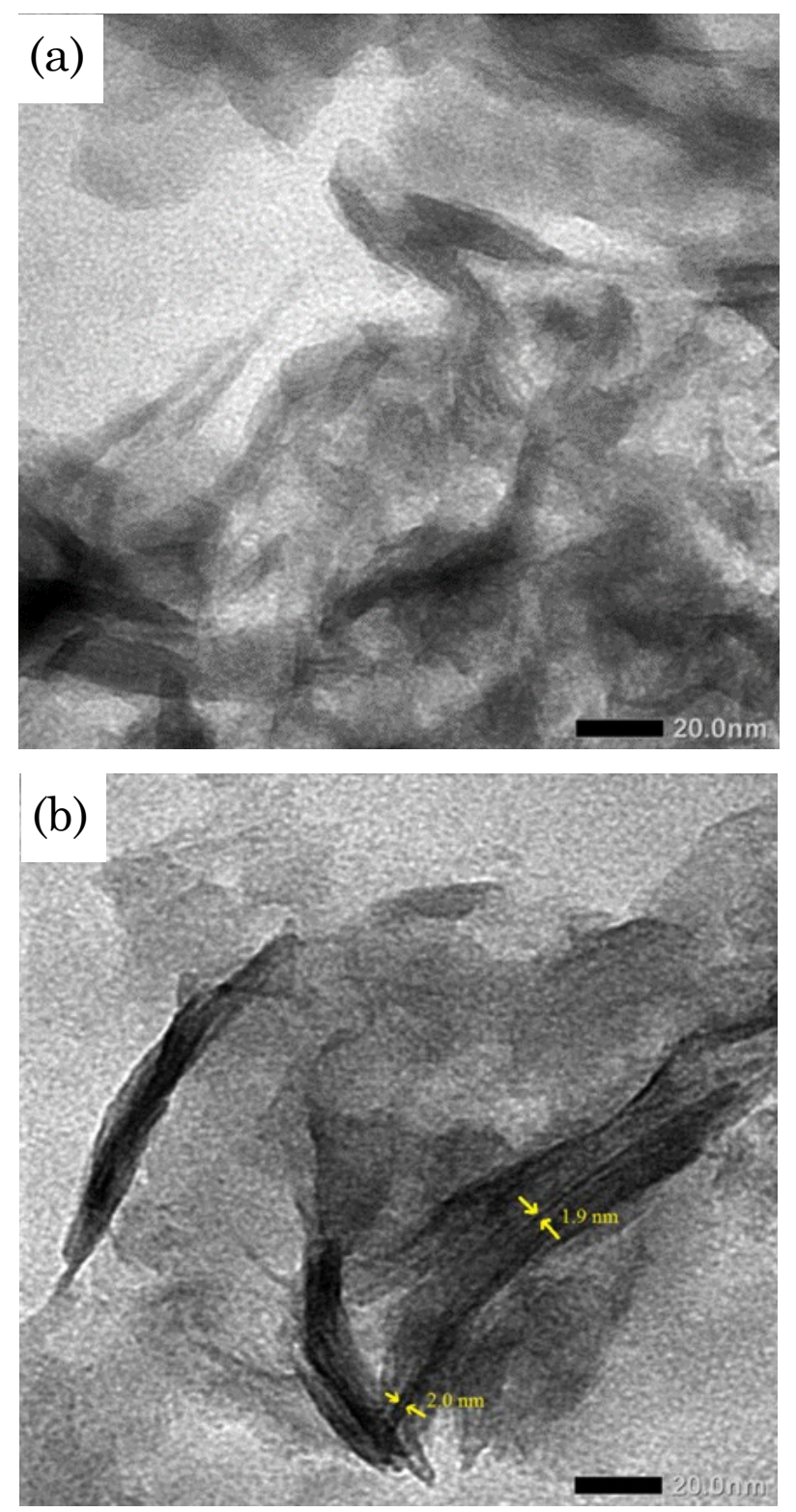

According to a previous research on citronellal conversion involving a solid catalyst and the mechanism presented in Scheme 1, the acid-catalyzed isomerization is not only caused by protonic $\left(\mathrm{H}^{+}\right)$species, but also by the presence of Lewis acidic species from the empty $d$ orbital provided by an active metal (in this case $\mathrm{Zn)}$.

Solid surface acidity represents the total Brønsted and Lewis acidities, and it was determined through pyridine adsorption followed by FTIR analysis (Figure 5). All samples demonstrated some absorption spectra related to the evolution of silica-alumina structure caused by the modification. All materials demonstrated the $\mathrm{Si}-\mathrm{O}$ asymmetric stretching vibration and the $\mathrm{Si}-\mathrm{O}-\mathrm{Si}$ deformation vibration, and these vibrations upshifted to 1056 and $468 \mathrm{~cm}^{-1}$, respectively. The presence of absorption bands at $2926-2946 \mathrm{~cm}^{-1}$ in the spectrum of $\mathrm{PCH}$ is associated with the rest intercalated template molecule which is specifically representing asymmetric and symmetric stretching vibrations of $\mathrm{CH}_{2}$ groups. The presence of surface acid sites was identified from the three major absorption bands, namely, 1450, 1490, and $1545 \mathrm{~cm}^{-1}$, which correspond to Lewis acidity, Brønsted and Lewis acidities, and Brønsted

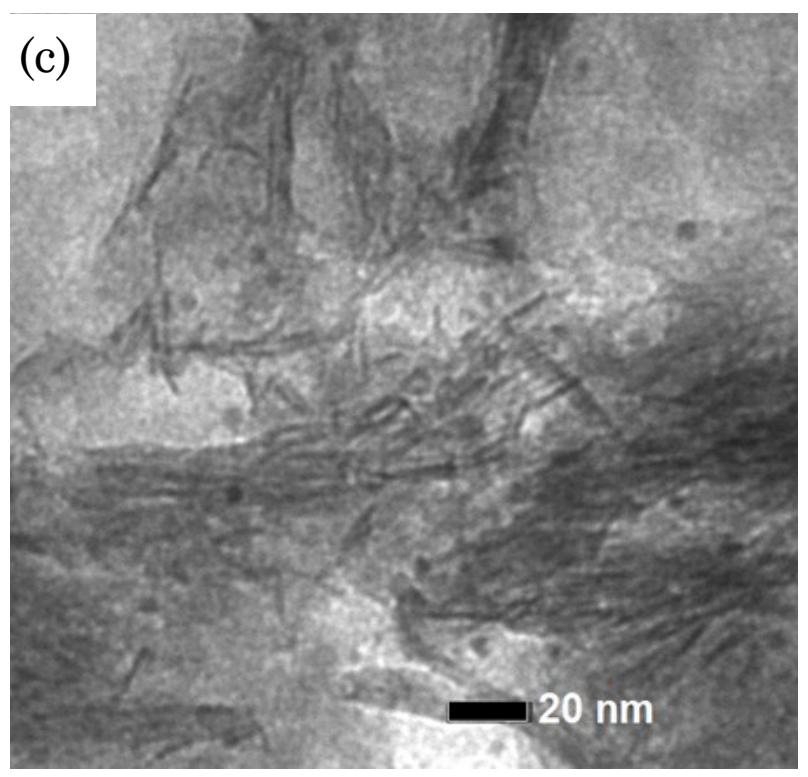

Figure 3. TEM profile of (a) Saponite (b) Zn/PCH-10 (b) Zn/PCH-30.

Table 2. Surface parameters and surface acidity.

\begin{tabular}{ccccc}
\hline Sample & $S_{\text {BET }}\left(\mathrm{m}^{2} / \mathrm{g}\right)$ & $\begin{array}{c}\text { Pore volume } \\
\left(\mathrm{cm}^{3} / \mathrm{g}\right)\end{array}$ & $\begin{array}{c}\text { Pore radius } \\
(\AA)\end{array}$ & $\begin{array}{c}\text { Surface acidity } \\
(\text { mol ethanolamine/g) }\end{array}$ \\
\hline Saponite & 110.12 & 0.0214 & 12.1 & 0.917 \\
Zn/PILS & 188.78 & $7.07 \times 10^{-2}$ & 17.88 & 1.152 \\
Zn/PCH & 770.22 & 0.7473 & 44.19 & 1.643 \\
\hline
\end{tabular}


acidity. By comparing SAP, Zn-PILC and Zn/ $\mathrm{PCH}$, it is seen that $\mathrm{Zn} / \mathrm{PCH}$ shows the more intensive spectrum as identification of both Brønsted and Lewis acid sites interaction with pyridine. The increasing surface acidity was also confirmed by the amount of surface acid sites as calculated by $n$-butylamine titration (Table 2). Moreover, the increasing surface acidity is consistent with the increasing specific surface area and pore volume as indicated by the adsorption-desorption profile (Figure 6a).

Table 2 shows the increasing specific surface area of saponite, and this trend is attributed to
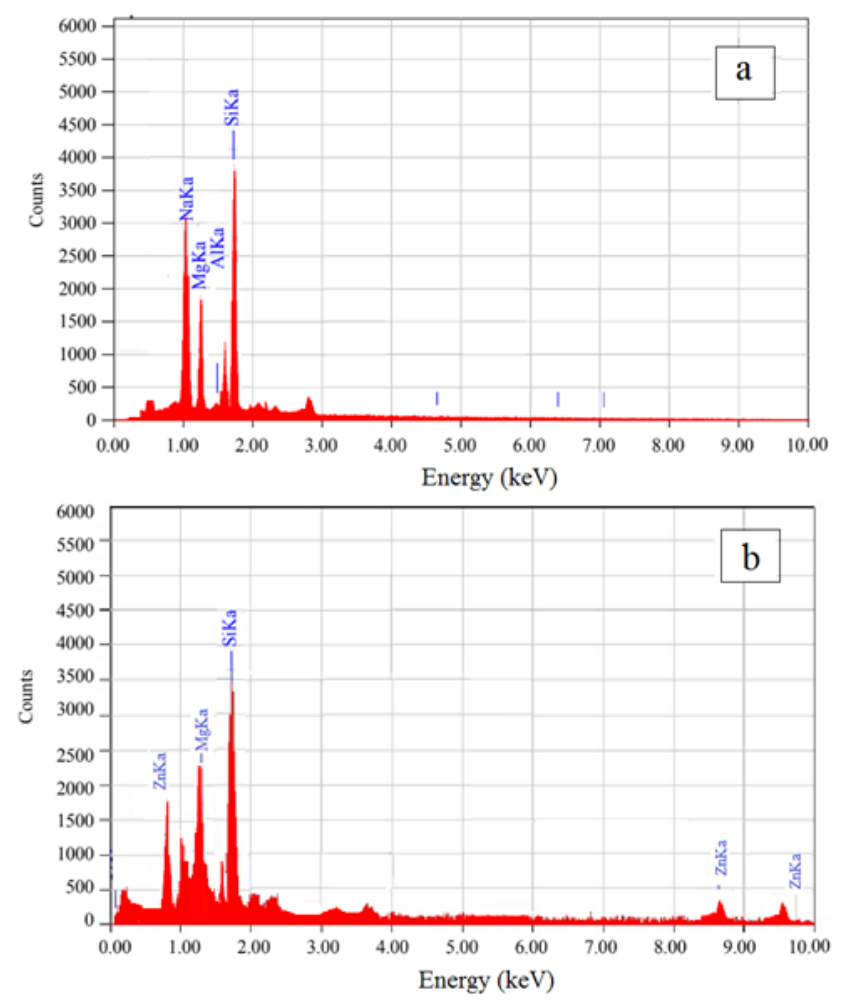

both pillarization and $\mathrm{PCH}$ formation. Data show that pillarization increased the specific surface area by approximately two-fold; by contrast, the specific surface area of $\mathrm{Zn} / \mathrm{PCH}$ increased by up to seven times with respect to that of saponite. The increasing specific surface area also corresponded with the increasing pore volume, which in turn was influenced by pore distribution (Figure 6b). The present values are similar to those reported for other metal-modified PCH prepared from saponite [9,21$25]$. The increasing surface area and pore volume was due to the formation of intra-gallery space from intercalation and due to pillar formation from silica. Moreover, the presence of proton $\left(\mathrm{H}^{+}\right)$from the framework formation enhanced the surface acidity. The increasing surface parameters and surface acidity contributed to the increasing catalytic activity as demonstrated in the kinetics of citronellal conversion (Figure 7).

$\mathrm{Zn} / \mathrm{PCH}$ displayed a superior activity as shown in the kinetics of citronellal conversion, demonstrating that nearly all citronellal were converted into a product after $2 \mathrm{~h}$ of reaction.

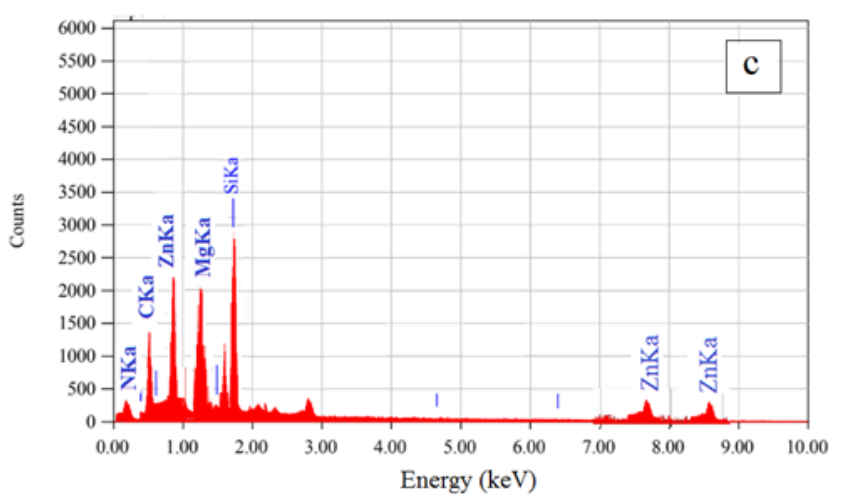

Figure 4. EDX spectra of (a) Saponite (b) Zn/PILS (c) Zn/PCH.

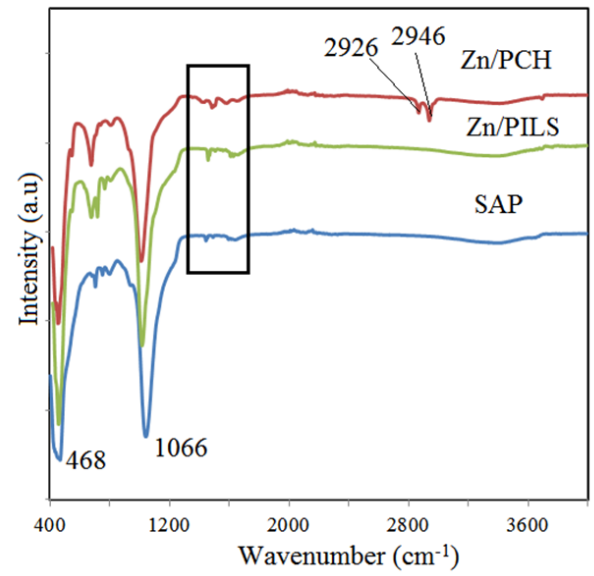

Figure 5. FTIR spectra of materials.
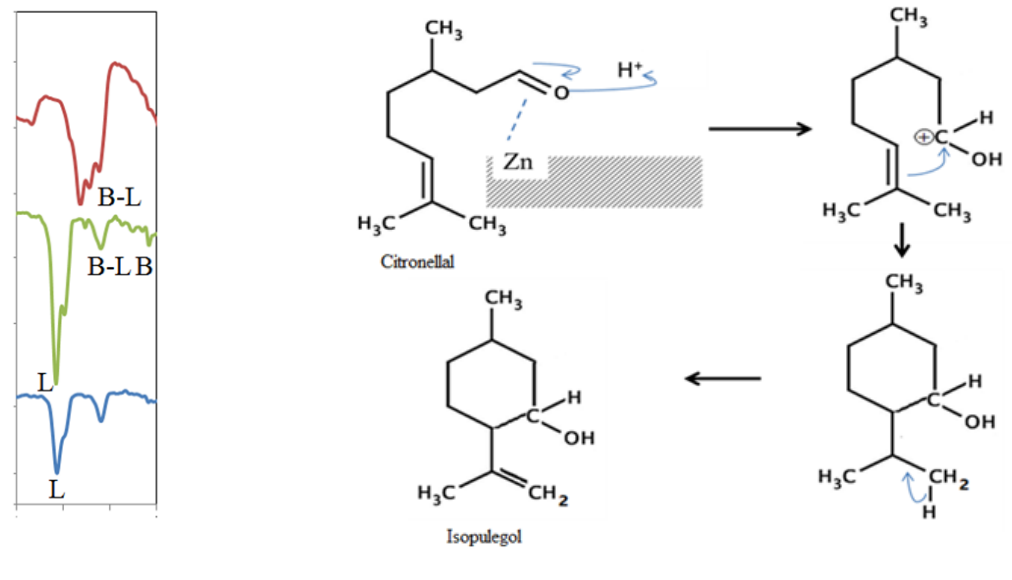

Scheme 1. Mechanism of citronellal conversion into isopulegol. 
In addition, the activity of Zn/PILS was intermediate to the activities of $\mathrm{Zn} / \mathrm{PCH}$ and saponite. All catalyzed reaction obeyed the pseudosecond order kinetics as shown by the fitness of the plot to Equation (3):

$$
\frac{1}{C_{t}}=k t+\frac{1}{C_{0}}
$$

where $C_{0}$ and $C_{t}$ are the initial citronellal concentration and the citronellal concentration at time $t$, respectively, and $k$ is the kinetics constant. The higher conversion rate is represented by the increasing kinetics constant from $0.003 / \% \mathrm{~h}$ for saponite to $0.027 / \% \mathrm{~h}$ for Zn/PILS and to an extreme extent of $43.22 / \% \mathrm{~h}$ for $\mathrm{Zn} / \mathrm{PCH}$. However, the constant kinetics order suggested that the catalytic mechanism was not altered. Not only on the catalytic conversion, $\mathrm{Zn} / \mathrm{PCH}$ also exhibits the isopulegol as main product of the conversion, demonstrating that cyclization mechanism was the main mechanism involved in the reaction. The higher selectivity to produce isopulegol of the $\mathrm{Zn} /$ PILC catalyst compared with Zn/PILS is also in the same order with catalytic conversion, suggesting the role of the increasing specific surface area and surface acidity in the catalytic mechanism. The catalytic activity of $\mathrm{Zn} / \mathrm{PCH}$ is comparable with that of clay-modified catalysts, such as sulfated zirconia-pillared montmorillonite, platinum dispersed on sulfated zirconia-pillared saponite, and nickel dispersed on sulfated zirconia-pillared saponite, which were used in previous citronellal conversion [16,2628]. All of the above-mentioned catalysts that demonstrated high conversion rate was tested in a microwave-assisted conversion under tandem cyclization-hydrogenation, which is an in-

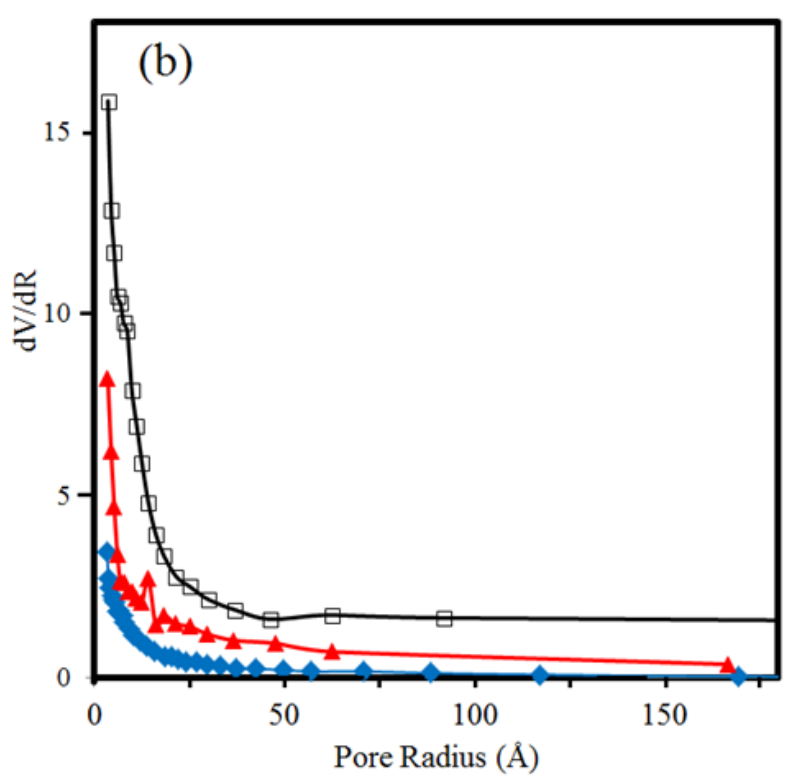

Figure 6. (a) Adsorption-desorption isotherm of materials, (b) Pore distribution of materials.
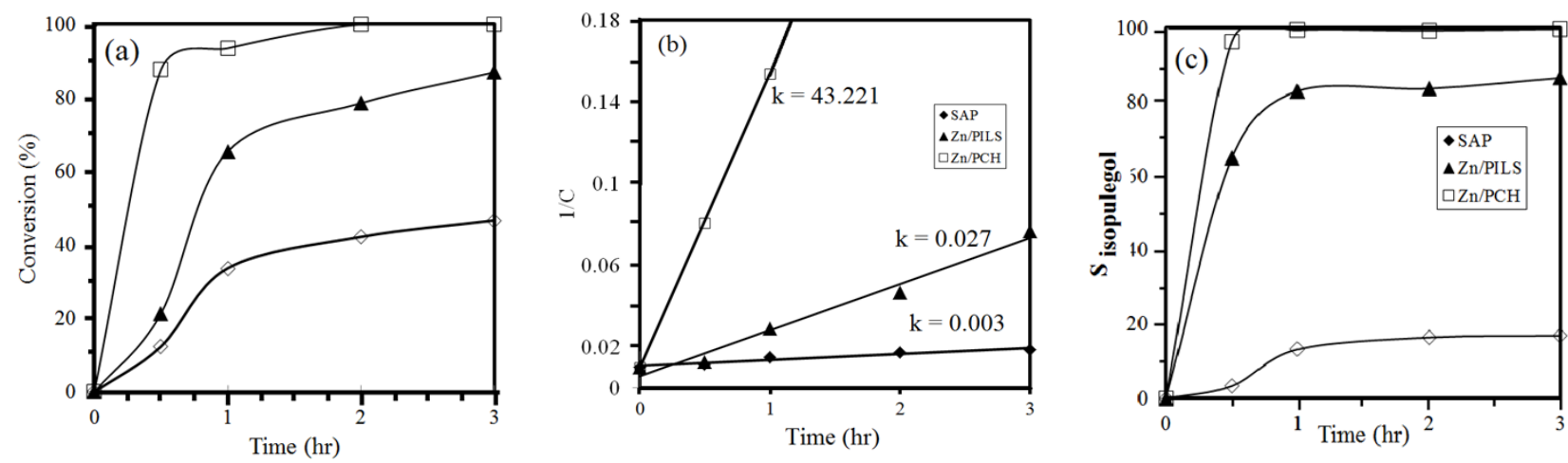

Figure 7. (a) Kinetics of citronellal conversion over varied catalyst, (b) pseudo-second order of kinetics, (c) Effect of reaction time on selectivity to isopulegol [catalyst weight: $0.15 \mathrm{~g}$; citronellal: $5 \mathrm{~mL}$; solvent: isopropanol]. 
tensive reaction mechanism. By contrast, the reaction system in this research was used only under reflux condition and without involving any other catalytic hydrogen transfer reagent. A selectivity of less than $100 \%$ represents other mechanisms wherein citronellal (1) conversion produces products other than isopulegol (2). GC -MS analysis results showed that there are two main by-products: menthone (3) and isomenthone (4). Both products are caused by the reductive condition in the conversion refer to the mechanism of citronellal conversion over $\mathrm{Al} / \mathrm{Fe}$ PIL (Scheme 2) [30].

The reductive condition causing the production of menthone and isomenthone products may be attributed to the catalytic hydrogen transfer mechanism of citronellal conversion over nickel dispersed on zirconia-pillared saponite and over nickel dispersed on sulfated zirconia pillared montmorillonite $[16,26]$. By comparing the selectivity when Zn/PILC and Zn/PILS were used and by considering the specific surface area of the catalyst utilized in a previous work [30], one may probably attribute the lower selectivity to the less specific surface area that contributed to the lower reactant transport by the surface. This limitation in selectivity should be intensively studied for fur-<smiles>CC(C)=CCCC(C)CC=O</smiles>

(1)

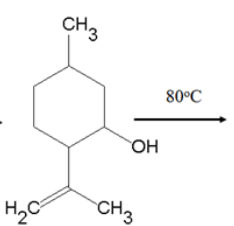

(2)

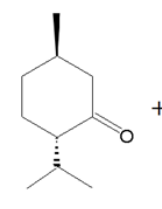

(3)

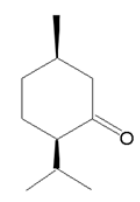

(4)

Scheme 2. Mechanism of citronellal conversion using Al/Fe-PILC.
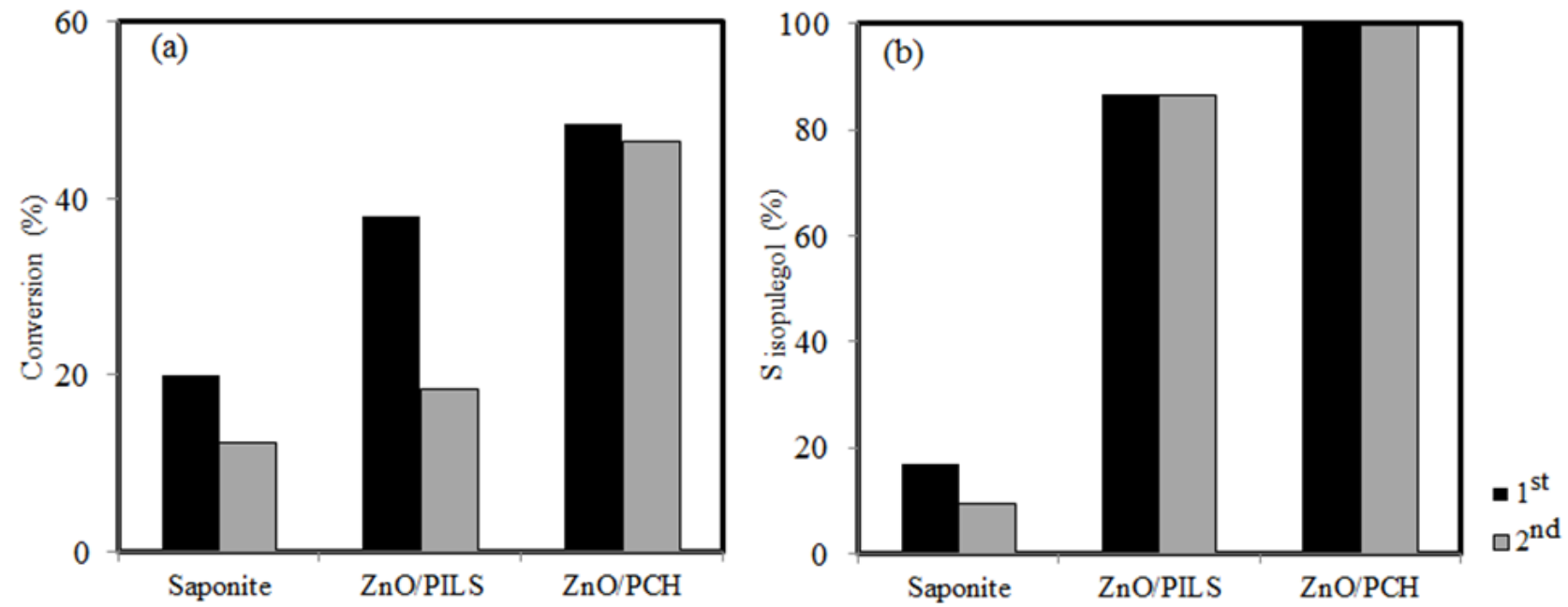

Figure 8. Comparison of fresh and recycled catalyst on (a) catalytic conversion, (b) selectivity in producing isopulegol. 
plication for citronellal conversion into isopulegol. The increasing performance is shown by increasing the kinetics constant from $0.003 / \% \mathrm{~h}$ for saponite to $0.027 / \% \mathrm{~h}$ and $43.22 / \% \mathrm{~h}$ for $\mathrm{Zn} /$ PILS and $\mathrm{Zn} / \mathrm{PCH}$, respectively. Moreover, the reusability of the $\mathrm{Zn} / \mathrm{PCH}$ catalyst is expressed by a relative unchanged total conversion and selectivity to produce isopulegol.

\section{Acknowledgment}

The authors would like to thank the Ministry of Research, Technology, and Higher Education for the financial support through the Penelitian Dasar Unggulan Perguruan Tinggi (012/Dir.DPPM/70/DPPM/Pen.Dasar UPTKemenristekdikti/III/2019) and the Directorate of Academic Development of the Universitas Islam Indonesia for the Travel Grant (HPKI 2019).

\section{References}

[1] Lenardão, E.J., Botteselle, G.V., de Azambuja, F., Perin, G., Jacob, R.G. (2007). Citronellal as key compound in organic synthesis. Tetrahedron, 63, 6671-6712.

[2] Chuah, G. (2001). Cyclisation of Citronellal to Isopulegol Catalysed by Hydrous Zirconia and Other Solid Acids. Journal of Catalysis, 200, 352-359.

[3] Fatimah, I., Rubiyanto, D., Huda, T., Yudha, S.P., Kartika, N.C. (2016). Novel sulphated zirconia pillared clay nanoparticles as catalyst in microwave assisted conversion of citronellal. Material Technology, 31(4), 222-228.

[4] González, B., Pérez, A.H., Trujillano, R., Gil, A., Vicente, M.A. (2017). Microwave-assisted pillaring of a montmorillonite with alpolycations in concentrated media. Materials, 10(8), 1-8.

[5] Kooli, F., Liu, Y., Hbaieb, K., Al-Faze, R. (2017). Preparation and catalytic activities of porous clay heterostructures from aluminiumintercalated clays: Effect of $\mathrm{Al}$ content. Clay Minerals, 52, 521-535.

[6] Chmielarz, L., Kowalczyk, A., Skoczek, M., Rutkowska, M., Gil, B., Natkański, P., Radko, M., Motak, M., Dębek, R., Ryczkowski, J. (2018). Porous clay heterostructures intercalated with multicomponent pillars as catalysts for dehydration of alcohols. Applied Clay Science, 160, 116-125.

[7] Saboya, R.M.A., Cecilia, J.A., García-Sancho, C., Luna, F.M.T., Rodríguez-Castellón, E., Cavalcante, C.L. (2016). $\mathrm{WO}_{3}$-based catalysts supported on porous clay heterostructures (PCH) with Si-Zr pillars for synthetic esters production. Applied Clay Science, 124-125, 69-78.

[8] Aznárez, A., Delaigle, R., Eloy, P., Gaigneaux, E.M., Korili, S.A., Gil, A.(2015).Catalysts based on pillared clays for the oxidation of chlorobenzene. Catalysis Today, 246, 15-27.

[9] Sanchis, R., Cecilia, J.A., Soriano, M.D., Vázquez, M.I., Dejoz, A., López-Nieto, J.M., Rodriguez-Castellón, E., Solsona, B. (2018). Porous clays heterostructures as supports of iron oxide for environmental catalysis. Chemical Engineering Journal, 334, 1159-1168.

[10] Cramarossa, M.R., Forti, L., Pagnoni, U.M., Vidali, M. (2016). Nickel oxide supported on porous clay heterostructures as selective catalysts for the oxidative dehydrogenation of ethane. Catalysis Science and Technology, 6(10), 3419-3429.

[11] Cecilia, J.A., García-Sancho, C., VilarrasaGarcía, E., Jiménez-Jiménez, J., RodriguezCastellón, E. (2018). Synthesis, Characterization, Uses and Applications of Porous Clays Heterostructures: A Review. Chemical Record, 18(7), 1085-1104.

[12] Kooli, F., Liu, Y., Hbaieb, K., Al-faze, R. (2016). Microporous and Mesoporous Materials Characterization and catalytic properties of porous clay heterostructures from zirconium intercalated clay and its pillared derivatives. Microporius and Mesoporous Materials, 226, 482-492.

[13] Chmielarz, L., Piwowarska, Z., Kuśtrowska, P., Węgrzyna, A., Gil, B., Kowalczyk, A., Dudek, B., Dziembaj, R., Michalik, M. (2011). Comparison study of titania pillared interlayered clays and porous clay heterostructures modified with copper and iron as catalysts of the DeNOx process. Applied Clay Science, 53(2), 164-173.

[14] Luna, F.M.T., Cecilia, J.A., Saboya, R.M.A., Barrera, D., Sapag, K., Rodríguez-Castellón, E., Cavalcante, C.L. (2018). Natural and modified montmorillonite clays as catalysts for synthesis of biolubricants. Materials, 11(9), 6-9.

[15] Molina, C.B., Casas, J.A., Pizarro, A., Rodriguez, J.J. (2011). Pillared Clays as Green Chemistry Catalysts: Application to Wastewater Treatment, in Clay: Types, Properties and Uses, 435-447.

[16] Fatimah, I., Rubiyanto, D., Huda, T., Handayani, S., Ilahi, O.M. (2015). Ni Dispersed on Sulfated Zirconia Pillared Montmorillonite as Bifunctional Catalyst in Eco- Friendly Citronellal Conversion. Engineering Journal, 19, 43-53. 
[17] Fatimah, I., Rubiyanto, D., Huda, T., Zuhrufa, Z., Yudha, S.P., Kartika, N.C. (2016). Novel sulphated zirconia pillared clay nanoparticles as catalyst in microwave assisted conversion of citronellal. Material Technology, 31(4), 222-228.

[18] Nisyak, K., Iftitah, E.D., Tjahjanto, R.T. (2017). Konversi Sitronelal Menjadi Senyawa Isopulegol dengan Katalis $\mathrm{ZnBr}_{2} / \mathrm{B}$-Zeolit. Jurnal Kimia dan Kemasan, 39, 47-54.

[19] Khedkar, M.V., Somvanshi, S.B., Humbe, A.V., Jadhav, K.M. (2019). Surface modified sodium silicate based superhydrophobic silica aerogels prepared via ambient pressure drying process. Journal of Non-Crystalline Solids, 511, 140-146.

[20] Fatimah, I., Yudha, S.P. (2017). N-[3(Trimethoxysilyl)propyl] ethylenediamine functionalized saponite as adsorbent of nickel from aqueous solution. Engineering Journal, 21(2), 107-121.

[21] Wang, Y., Su, X., Xu, Z., Wen, K., Zhang, P., Zhu, J., He, H. (2016). Preparation of surfacefunctionalized porous clay heterostructures via carbonization of soft-template and their adsorption performance for toluene. Applied Surface Science, 363, 113-121.

[22] Tassanapayak, R., Magaraphan, R., Manuspiya, H. (2008). Functionalized porous clay heterostructure for heavy metal adsorption from wastewater. Advanced Materials Research, 55-57, 617-620.
[23] Pinto, M.L., Marques, J., Pires, J. (2012). Porous clay heterostructures with zirconium for the separation of hydrocarbon mixtures. Separation and Purification Technology, 98, 337343.

[24] Zhao, P., Zhu, L. (2016). Optimized porous clay heterostructure for removal of acetaldehyde and toluene from indoor ai. Frontier Environmental Science Engineering, 10, 219228.

[25] Polverejan, M., Pauly, T.R., Pinnavaia, T.J. (2000). Acidic porous clay heterostructures (PCH): Intragallery assembly of mesoporous silica in synthetic saponite clays. Chemistry of Materials, 12, 2698-2704.

[26] Fatimah, I., Rubiyanto, D., Huda, T. (2015). Preparation and characterization of $\mathrm{Ni} / \mathrm{Zr}$ Saponite as catalyst in catalytic hydrogen transfer reaction of isopulegol. Material Science Forum, 827, 311-316.

[27] Fatimah, I. (2009). Zirconium dioxide dispersed in SiO2-montmorillonite: Heterogeneous catalyst for citronellal conversion to isopulegol. Journal of Applied Science Research, 5, 1277-1284.

[28] Cramarossa, M.R., Forti, L., Pagnon, U.M., Vidali, M. (2001). Cyclization of Citronellal to Menthone and Isomenthone Catalyzed by Al/Fe-Pillared Clay. Synthesis, 2, 52-54. 